\title{
Long-term survival after composite mechanical aortic root replacement: A consecutive series of 448 cases
}

\author{
Christian D. Etz, MD, PhD, Konstantin von Aspern, MD, Felix F. Girrbach, MD, Roberto R. Battellini, MD, PhD, \\ Oemuer Akhavuz, MD, Sergey Leontyev, MD, Michael A. Borger, MD, PhD, Pascal M. Dohmen, MD, PhD, and \\ Friedrich-Wilhelm Mohr, MD, PhD
}

Objective: To determine the effect of different etiologies on the outcome and mortality after mechanical composite aortic root/ascending replacement.

\begin{abstract}
Methods: From February 1998 to June 2011, 448 consecutive patients (358 men, age, $52.8 \pm 12.3$ years) underwent composite mechanical aortic root replacement. Of these 448 patients, $362(80.8 \%)$ were treated for degenerative/atherosclerotic root/ascending aortic aneurysm (287 men, age, $53.0 \pm 12.1$ years), 65 $(14.5 \%)$ for emergent acute type A aortic dissection (49 men, age, $51.0 \pm 13.1$ years), and 21 (4.7\%) for active infective endocarditis ( 20 men, age, $46.5 \pm 13.6$ years); $15 \%(\mathrm{n}=68)$ were reoperative or redo procedures.

Results: The overall hospital mortality after composite root/ascending replacement was $6.7 \%(\mathrm{n}=30)$. It was $3.9 \%(\mathrm{n}=14)$ after elective/urgent aneurysm replacement, $20.0 \%(\mathrm{n}=13)$ after emergency repair for acute type A aortic dissection, and $14.3 \%$ for active infective endocarditis $(n=3)$. The overall 1-year mortalityas a measure of operative success-was $5.2 \%(n=19)$ after elective/urgent degenerative/atherosclerotic root/ascending aortic aneurysm repair, $21.5 \%(\mathrm{n}=14)$ after emergency repair for acute type A aortic dissection, and $14.3 \%(\mathrm{n}=3)$ after active infective endocarditis (degenerative/atherosclerotic root/ascending aortic aneurysm vs acute type A aortic dissection, $P=.03$; degenerative/atherosclerotic root/ascending aortic aneurysm vs active infective endocarditis, $P=.08$; acute type A aortic dissection vs active infective endocarditis, $P=.8$ ). Long-term survival was $88.3 \%$ at 5 years and $72.2 \%$ at 10 years, with a linearized mortality rate after 30 days of $2.5 \%$ patient-year. Long-term survival after surgery for acute type A aortic dissection and active infective endocarditis was $72 \%$ and $72.3 \%$ at 5 years and $64.9 \%$ and $62 \%$ at 10 years, respectively, with a linearized mortality rate of $2.6 \%$ patient-year for acute type A aortic dissection and $3.7 \%$ for active infective endocarditis. Survival after composite root replacement after the first year paralleled that of an age- and gender-matched population, regardless of the etiology. Women appeared to have less favorable longevity.
\end{abstract}

Conclusions: Composite root replacement remains a versatile choice for various pathologic features with excellent longevity and freedom from reoperation and should be strongly considered if conditions for valve-sparing repair are less than perfect. (J Thorac Cardiovasc Surg 2013;145:S41-7)

Bentall and De Bono originally described their technique for complete replacement of the aortic valve and ascending aorta in a patient presenting with free aortic regurgitation in 1968. They used a mechanical composite graft-consisting of a no. 13 Starr cage-ball valve attached to a crimped Teflon tube-for aortic root replacement with reattachment of the 2 main coronary arteries. Nine years later, in 1977, Kouchoukos and colleagues ${ }^{1}$ published their initial experience

\footnotetext{
From the Department of Cardiac Surgery, Heart Center Leipzig, University of Leipzig, Saxony, Germany.

Disclosures: Drs Etz, von Aspern, Girrbach, Battellini, Akhavuz, Leontyev, Borger, Dohmen, and Mohr have nothing to disclose with regard to commercial support. Presented at the American Association for Thoracic Surgery Aortic Surgery Symposium 2012, April 26-27, 2012, New York, NY.

C.D.E. and K.v.A. contributed equally to this study.

Received for publication May 21, 2012; revisions received Oct 17, 2012; accepted for publication Nov 20, 2012.

Address for reprints: Christian D. Etz, MD, PhD, Department of Cardiac Surgery, University of Leipzig, Heart Center Leipzig, Struempellstr 39, Leipzig 04289, Germany (E-mail: christian.etz@med.uni-leipzig.de).

$0022-5223 / \$ 36.00$

Copyright (c) 2013 by The American Association for Thoracic Surgery

http://dx.doi.org/10.1016/j.jtcvs.2012.11.045
}

of 25 cases using coronary buttons. The Button-Bentall became one of the most significant refinements of the classic procedure. $^{1}$ In 1996, Bachet and colleagues ${ }^{2}$ were the first to report an extensive experience of more than 200 patients, demonstrating the superiority of the Button-Bentall and its successful use for various etiologies.

In the early 1990s, Galla and colleagues, ${ }^{3}$ introduced the BioBentall-a home-made composite graft manufactured intraoperatively using a stented bioprosthesis-enabling root replacement in patients deemed unable to take anticoagulants. The BioBentall provided excellent long-term survival and very low rates of thromboembolism, bleeding complications, and reoperation., ${ }^{4,5}$

During the past decade, valve-sparing procedures have progressively been recommended for aortic root repair, especially in younger patients. Excellent patient survival and durability of aortic valve function in highly selected patients with root aneurysm and normal or near-normal aortic valve leaflets has been reported, particularly with the reimplantation technique. ${ }^{6-8}$ The excellent clinical 
Abbreviations and Acronyms
ADA = acute type A aortic dissection
AIE = active infective endocarditis
CVA $=$ cerebrovascular accident
LMR $=$ linearized mortality rate
$\mathrm{R} / \mathrm{AsA}=$ degenerative or atherosclerotic aortic root/ascending ectasia/aneurysm

outcome in selected patients and the lack of a need for anticoagulation generated increasing interest in extending the indications for valve-sparing procedures. ${ }^{9,10}$ Increasing reports have emerged on extensive aortic valve repair even of bicuspid valves with a calcified raphe. ${ }^{11}$

Recently, Urbanski and colleagues ${ }^{5}$ reported the successful use of composite grafts with oversized biologic valves, particularly in patients with a small native annulus $(<23$ $\mathrm{mm}$ ). They suggested the biologic valve composite graft as an alternative for younger patients because of the ease of reoperative replacement of the biologic valve in the rare case of deterioration. ${ }^{5}$

The objective of the present analysis was to provide benchmark data from the largest contemporary single-center experience of mechanical composite aortic root replacement.

\section{METHODS}

A review of the institutional database — of more than 1200 aortic root procedures-disclosed 448 consecutive patients who underwent isolated mechanical composite aortic root replacement from February 1998 to June 2011. The indications for surgery were pathologic features affecting the aortic valve in the presence of root/ascending aorta disease. These included degenerative or atherosclerotic aortic root/ascending ectasia/aneurysm (R/AsA), acute type A aortic dissection (ADA), and active infective endocarditis (AIE) of a native/prosthetic aortic valve. Patients requiring concomitant full arch repair were excluded $(n=26)$ to allow for objective comparison of root procedures. The institutional review board approved the present research, and additional patient consent was not required.

\section{Patient Demographics and Indication for Surgery}

A total of 448 patients (mean age, $52.8 \pm 12.3$ years; range, 18 - 88 years) underwent mechanical composite aortic root replacement with a single conduit type (size, 21-29 mm; ATS Medical, Minneapolis, Minn). Of these patients, 362 were treated for R/AsA, 65 for ADA, and 21 for AIE. Aortic valve dysfunction was observed in 438 of the patients $(98 \%)$ and was isolated stenosis $(10 \%)$ or regurgitation $(57 \%)$, or a combination of both $(31 \%)$. The clinical characteristics of all patients are listed in Table 1.

\section{Indications for Root/Ascending Replacement}

Patients with R/AsA. Most patients underwent surgery for various aortic valve pathologic entities combined with root/ascending ectasia or aneurysm $(\mathrm{n}=352$, aneurysm in 270 and ectasia in 82$)$. Ten patients presented with an aneurysm strictly limited to the aortic root. Two patients underwent aortic root replacement after valve repair was unsuccessful. One patient underwent initial valve replacement and supracommissural ascending replacement, which resulted in distortion of the coronary ostia, warranting complex root revision. Finally, 42 patients $(12 \%)$ had undergone previous cardiac surgery. Of those, 26 (62\%) had undergone previous aortic surgery. Patients with ADA. A total of 65 patients underwent emergency surgery for ADA. Patients with iatrogenic dissections $(n=6)$ were excluded owing to the confounding nature of the initial surgery. Eleven patients had undergone previous aorta-related surgery. Two patients had aortic type A repeat dissection at the root level (one bicuspid and one tricuspid) after previous aortic valve-sparing repair with supracommissural ascending replacement. One had undergone previous supracommissural ascending replacement, required reoperative root repair (valve-remodeling, Yacoub), experienced annulus perforation, and, eventually, received a mechanical composite graft at his third reoperation. Three patients had previously undergone isolated supracommissural ascending replacement $(1,3$, and 4 years before their aortic root dissected). Five patients had undergone previous aortic valve replacement and their aorta dissected late at 2, 6, 13 , and 15 years after the previous surgery. One patient experienced annulus perforation 12 years after redo aortic valve surgery.

Patients with AIE. A total of 21 patients underwent urgent surgery for AIE of the aortic valve. A native aortic valve was present in 7 patients, and 14 patients had prosthetic valve endocarditis. A root abscess was found in 7 (native in 4 and prosthetic in 3). Previous endocarditis had occurred in 3 (all prosthetic), and concomitant mitral valve endocarditis was found in 2 patients. Of the 21 patients, $16(76 \%)$ had undergone previous aortic valve and/or ascending aortic replacement. One patient had undergone a Bentall procedure 5 years previously to redo mechanical composite root replacement for a pseudoaneurysm involving the right coronary button. The patient also required mitral valve repair at reoperation.

\section{Surgical Technique}

Cannulation. Arterial cannulation was direct-either by the ascending aorta $(n=240)$ or the proximal arch $(n=97)$-in $75 \%$. In 1 case, primary cannulation of the carotid artery was used. The femoral artery was used in 51 patients $(11 \%)$. This was by preference of the surgeon in $24(47 \%)$, for emergency arterial access in $13(25.5 \%)$, because the aneurysm included the aortic arch with no direct cannulation site available in 12 $(23.5 \%)$, or because of a previous reoperative sternotomy in $2(4 \%)$.

Temperature management and cerebral protection. Surgery was usually performed with mild-to-moderate hypothermia $\left(30^{\circ} \mathrm{C}\right)$ with an average minimal core temperature (bladder) of $29.3^{\circ} \pm 6^{\circ} \mathrm{C}$. In 370 patients $(83 \%)$, the distal ascending aorta was clamped during completion of the distal anastomosis (R/AsA, 314 [87\%]; ADA, 36 [55\%]; and AIE, 20 [95\%]).

In 30 patients $(7 \%)$, antegrade selective cerebral perfusion was established as an adjunct to hypothermic distal circulatory arrest, and open distal anastomosis was performed (R/AsA, 13 [3.6\%]; ADA, 17 [28\%]; AIE, $0[0 \%]$ ), with a mean temperature of $23.9^{\circ} \mathrm{C} \pm 5^{\circ} \mathrm{C}$. Cannulation for antegrade selective cerebral perfusion was unilateral in 11 or bilateral using a perfusion catheter in the left carotid artery in 19, as previously described. Hypothermic circulatory arrest without antegrade selective cerebral perfusion was used in $48(11 \%)$.

Aortic root replacement. The Button-Bentall procedure as modified by Kouchoukos ${ }^{12}$ was performed in all patients, using 1 type of mechanical composite conduit (ATS Medical). The mean prosthesis size was $25 \pm 2 \mathrm{~mm}$ (range, 21-29 $\mathrm{mm}$ ).

Partial aortic arch replacement. A total of 74 patients underwent concomitant partial aortic arch replacement because of involvement of the proximal aortic arch in the aneurysm or dissection (R/AsA, 46 [13\%]; ADA, 26 [40\%]; and AIE, 2 [9.5\%]). In these cases, the concavity of the aortic arch was resected, leaving the convexity of the transverse arch, including the origin of the supraaortic vessels.

Concomitant procedures. Coronary artery bypass grafting was performed in 58 patients $(13 \%)$, with an average of 1.8 bypass grafts (range, 1-5 grafts) per patient. Mitral valve surgery was undertaken in 35 patients (replacement in 14 and repair in 21). Nine patients underwent 
TABLE 1. Clinical profile and intraoperative data

\begin{tabular}{|c|c|c|c|c|}
\hline Variable & All & R/AsA & ADA & AIE \\
\hline Patients (n) & $448(100)$ & $362(80.8)$ & $65(14.5)$ & $21(4.7)$ \\
\hline \multicolumn{5}{|l|}{ Age (y) } \\
\hline Mean \pm SD & $52.8 \pm 12$ & $53 \pm 12$ & $51 \pm 13$ & $47 \pm 14$ \\
\hline Range & $18-88$ & $18-88$ & $20-87$ & $28-71$ \\
\hline Age $>60 y$ & $141(32)$ & $123(34)$ & $14(22)$ & $4(19)$ \\
\hline Male gender & $356(80)$ & $287(79)$ & $49(75)$ & $20(95)$ \\
\hline Previous cardiac operations & $68(15)$ & $42(12)$ & $11(14)$ & $17(81)$ \\
\hline Previous aortic operations & $52(12)$ & $26(7.2)$ & $11(14)$ & $17(81)$ \\
\hline Previous MV replacement & $14(3)$ & $12(3)$ & $0(0)$ & $2(10)$ \\
\hline Previous MV repair & $21(5)$ & $18(5)$ & $1(2)$ & $2(10)$ \\
\hline CABG & $58(13)$ & $46(13)$ & $11(17)$ & $1(5)$ \\
\hline \multicolumn{5}{|l|}{ Timing of surgery } \\
\hline Elective & $320(71)$ & $313(86)$ & $3 *(5)$ & $4(19)$ \\
\hline Urgent & $51(11)$ & $36(10)$ & $7(10)$ & $8(38)$ \\
\hline Emergent & $77(17)$ & $13(4)$ & $55(85)$ & $9(43)$ \\
\hline \multicolumn{5}{|l|}{ Risk factors } \\
\hline LVEF $\leq 30 \%$ & $14(3)$ & $13(4)$ & $1(2)$ & $0(0)$ \\
\hline History of hypertension & $252(56)$ & $208(57)$ & $35(54)$ & $9(43)$ \\
\hline Coronary artery disease & $64(14)$ & $54(15)$ & $9(14)$ & $1(5)$ \\
\hline Smoking & $117(26)$ & $97(27)$ & $14(22)$ & $6(29)$ \\
\hline IDDM & $24(5)$ & $23(6)$ & $1(15)$ & $0(0)$ \\
\hline COPD & $11(3)$ & $9(2)$ & $1(2)$ & $1(5)$ \\
\hline Previous CVA & $14(3)$ & $10(3)$ & $1(2)$ & $3(14)$ \\
\hline \multicolumn{5}{|l|}{ Intraoperative findings } \\
\hline Aortic stenosis & $45(10)$ & $39(11)$ & $3(5)$ & $3(14)$ \\
\hline Aortic regurgitation & $253(57)$ & $192(53)$ & $58(89)$ & $3(14)$ \\
\hline Both & $140(31)$ & $130(36)$ & $4(6)$ & $6(29)$ \\
\hline Ascending diameter (mm) & $55.1 \pm 10.9$ & $54.8 \pm 9.7$ & $73.9 \pm 23.4$ & $52.0 \pm 6.6$ \\
\hline \multicolumn{5}{|l|}{$\mathrm{CPB}$} \\
\hline Direct cannulation & $337(75)$ & $305(84)$ & $13(20)$ & $19(90)$ \\
\hline Femoral cannulation & $51(11)$ & $35(10)$ & $15(23)$ & $1(5)$ \\
\hline Axillary cannulation & $60(13)$ & $22(6)$ & $37(57)$ & $1(5)$ \\
\hline Crossclamp time (min) & $94.97 \pm 39.0$ & $89.6 \pm 34.2$ & $112.3 \pm 49.2$ & $118.2 \pm 40.3$ \\
\hline CPB time (min) & $148.0 \pm 81.1$ & $137.3 \pm 75$ & $196.8 \pm 91$ & $187.3 \pm 76$ \\
\hline \multicolumn{5}{|l|}{ Myocardial protection } \\
\hline Cold antegrade blood & $73(16)$ & $56(15)$ & $11(17)$ & $6(29)$ \\
\hline Crystalloid cardioplegia $\dagger$ & $375(84)$ & $306(85)$ & $54(83)$ & $15(71)$ \\
\hline
\end{tabular}

Data presented as mean \pm standard deviation or $\mathrm{n}(\%) . R / A s A$, Degenerative or atherosclerotic aortic root/ascending ectasia/aneurysm; $A D A$, acute type A aortic dissection; $A I E$, active infective endocarditis; $M V$, mitral valve; $C A B G$, coronary artery bypass grafting; $L V E F$, left ventricular ejection fraction; $I D D M$, insulin-dependent diabetes mellitus; $C O P D$, chronic obstructive pulmonary disease; $C V A$, cerebrovascular accident; $C P B$, cardiopulmonary bypass; $S D$, standard deviation. *Chronic. $\dagger$ Bretschneider HTK, Köhler Chemie, Alsbach-Hähnlein, Germany.

septal myectomy for hypertrophic left ventricular outflow tract obstruction. Minor concomitant procedures included cryoablation or radiofrequency ablation in 11 and left atrial appendage ligation in 4.

\section{Follow-up}

The patients were followed up by the referring cardiologist and contacted periodically by our research personnel either through outpatient visit and telephone interviews or by questionnaire. The follow-up data were $100 \%$ complete, with a mean duration of $5.8 \pm 3.7$ years (range, 0.1 13.1 years; median, 6.3 years) and was closed July 18, 2011.

\section{Statistical Analysis}

Data were imported to SPSS, version 17.0 (SPSS, Chicago, Ill) for description and analysis. Differences between groups were analyzed using the Student $t$ test and chi-square test, as appropriate. Kaplan-Meier curves were calculated and tested by log-rank analysis to describe the differences in long-term survival among the groups. All tests were performed as 2 -sided at a significance level of $5 \%$.

Factors influencing survival were initially explored by separate univariate analyses, each considering factors related to in-hospital or long-term death. After the univariate analysis, the factors that showed a significant influence on survival were analyzed by multivariate analyses using either Cox regression analysis for time-dependent data or logistic regression analysis for binary data. Risk factor analyses were performed separately for each and for all etiologies combined.

\section{RESULTS}

\section{Hospital Mortality}

The overall hospital mortality (defined as death before discharge or within 30 days after surgery), including all 
emergencies, regardless of etiology, was $6.7 \%(n=30)$. For elective or urgent repair, it was $3.9 \%$ (14/362), without significant differences between the primary and reoperative patients $(3.4 \%[11 / 320]$ vs $7.1 \%[3 / 42], P=.223)$. The in-hospital mortality for R/AsA was significantly lower than for emergency surgery for ADA or urgent operation for AIE (ADA, $20.0 \%, \mathrm{n}=13 / 65, P=.001$; and AIE, $14.3 \%, \mathrm{n}=3 / 21, P=.003)$. For ADA and AIE, the inhospital mortality was comparable $(P=.750)$. Adjustment for age and gender when comparing R/AsA with ADA and AIE did not alter the statistical significance.

\section{Postoperative Course and Complications}

The overall prevalence of postoperative complications showed no significant difference between the etiologic subgroups ( $P=.536$; Table 2$)$, except for sepsis (R/AsA, $\mathrm{n}=4$ $[1.1 \%]$; ADA, $\mathrm{n}=5$ [7.7\%]; AIE, $\mathrm{n}=1[4.8 \%] ; P=.003)$ and respiratory failure (R/AsA, $\mathrm{n}=19[5.2 \%]$; ADA, $\mathrm{n}=10[15.4 \%] ;$ AIE, $\mathrm{n}=2[9.5 \%] ; P=.012)$.

\section{Long-Term Survival, Linearized Mortality Rates, and Comparison With an Age- and Gender-Matched Normal Population}

The overall survival after 14 years for R/AsA was $63 \%$ and $70.3 \%$ for all primary elective and urgent patients $(P=.212)$. Detailed 1-year mortality and 5- and 10-year survival data are listed in Table 3 . The patients after surgery for R/AsA had a linearized mortality rate (LMR, after 30 days) of $2.5 \%$ /patient-year. For patients with ADA, the LMR was $2.6 \%$, and for AIE, it was 3.7\%/patient-year. A comparison of the survival of the entire cohort with an

TABLE 2. Postoperative complications and cause of death

\begin{tabular}{|c|c|c|c|c|c|}
\hline Variable & All & R/AsA & ADA & AIE & $\begin{array}{c}P \\
\text { value }\end{array}$ \\
\hline \multicolumn{6}{|l|}{$\begin{array}{l}\text { Postoperative } \\
\text { complications }\end{array}$} \\
\hline $\begin{array}{l}\text { Hemodynamically } \\
\text { relevant arrhythmia }\end{array}$ & $44(9.8)$ & $37(10.2)$ & $3(4.6)$ & $4(19.0)$ & .134 \\
\hline Bleeding & $68(15.2)$ & $53(14.6)$ & $14(21)$ & $1(4.8)$ & .118 \\
\hline Sepsis & $10(2.2)$ & $4(1.1)$ & $5(7.7)$ & $1(4.8)$ & .003 \\
\hline CPR & $12(2.7)$ & $10(2.8)$ & $2(3.1)$ & $0(0)$ & .739 \\
\hline Stroke & $24(5.4)$ & $19(5.2)$ & $5(7.7)$ & $0(0)$ & .437 \\
\hline New dialysis & $1(0.2)$ & $1(0.3)$ & $0(0)$ & $0(0)$ & .911 \\
\hline Respiratory failure & $31(6.9)$ & $19(5.2)$ & $10(15.4)$ & $2(9.5)$ & $.012 *$ \\
\hline \multicolumn{6}{|l|}{ Cause of death } \\
\hline Multiorgan failure & $6(1.3)$ & $4(1.1)$ & $1(1.5)$ & $1(4.8)$ & .414 \\
\hline Acute heart failure & $15(3.3)$ & $11(3.0)$ & $2(3.1)$ & $2(9.5)$ & .334 \\
\hline $\begin{array}{l}\text { Acute respiratory } \\
\text { failure }\end{array}$ & $6(1.3)$ & $4(1.1)$ & $1(1.5)$ & $1(4.8)$ & .426 \\
\hline Other $\dagger$ & $67(15.0)$ & $48(13.3)$ & $17(26.2)$ & $2(9.5)$ & $.023 *$ \\
\hline
\end{tabular}

age- and gender-matched, normal East German population is shown in Figures 1 and 2. Despite less favorable shortterm outcomes for patients with ADA and AIE compared with those with R/AsA, the long-term outcome was equivalent among the groups $(P=.733$; Figure 3$)$.

\section{Long-Term Adverse Events and Freedom From Reoperation}

The complications considered during long-term followup were aorta-related reoperation, stroke, and severe bleeding. Stroke accounted for $4.5 \%$ of adverse events during long-term follow-up $(\mathrm{n}=20$; R/AsA, $\mathrm{n}=16$ [4.4\%]; ADA, $\mathrm{n}=4[6.2 \%]$; AIE, $\mathrm{n}=0$ ) occurring 1 to 12 years postoperatively (median, 6.4 years). Severe bleeding complications occurred in 5 patients $(2 \%)(\mathrm{R} / \mathrm{AsA}, \mathrm{n}=4$ [1.1\%]; ADA, $\mathrm{n}=1[1.5 \%]$; AIE, $\mathrm{n}=0$ ) 3 to 9 years postoperatively (median, 7.2 years; with gastrointestinal bleeding in 3 and intramuscular bleeding in 1). Only 1 patient experienced spontaneous cerebrovascular hemorrhage, with no previous reported trauma. Freedom from aorta-related reoperation during the entire follow-up period was $98 \%$ for the patients with R/AsA $(n=6), 92 \%$ for those with ADA $(n=5)$, and $86 \%$ for those with $\operatorname{AIE}(\mathrm{n}=3)$.

\section{Elective Patients With Pure Regurgitation for Comparison}

We compiled an artificially assembled cohort that was potentially eligible for valve-sparing procedures and for comparison purposes only consisting of patients who had undergone elective and urgent primary surgery for R/AsA and urgent surgery for ADA and who had isolated aortic regurgitation (mean age, $53.5 \pm 12.2$ years). The overall hospital mortality was $1.1 \%(1 / 89)$ for this group. The overall prevalence of postoperative complications was not significantly different from that for the entire cohort. The overall 1 -year mortality in this cohort was 5.6\% (5/89) with 5- and 10 -year survival of $92 \%$ and $78 \%$, respectively. The LMR was $2.3 \%$ /patient-year. Freedom from aorta-related reoperation was $97.8 \%$ at 10 years. Freedom from bleeding or thromboembolic events was $98.9 \%$ and $95.6 \%$ at 5 and 10 years, respectively.

\section{Risk Factors}

Multivariate analysis of all deaths occurring after mechanical composite aortic root replacement identified age, previous cerebrovascular accidents (CVAs), and emergency surgery as highly significant risk factors (Table 1 and Figure 1). Female gender and a prolonged crossclamp time during surgery also had a significant adverse effect on survival. The adverse effect of aortic reoperation on survival was of borderline significance $(P=.072)$. In patients undergoing surgery for ADA, a reduced left ventricular ejection fraction was associated with an eightfold increased 
TABLE 3. Mortality and survival

\begin{tabular}{|c|c|c|c|c|c|c|}
\hline \multirow[b]{2}{*}{ Variable } & \multirow[b]{2}{*}{ R/AsA } & \multirow[b]{2}{*}{ ADA } & \multirow[b]{2}{*}{ AIE } & \multicolumn{3}{|c|}{$P$ value } \\
\hline & & & & R/AsA vs ADA & R/AsA vs AIE & ADA vs AIE \\
\hline \multicolumn{7}{|l|}{ Mortality } \\
\hline In-hospital & $3.9(14 / 362)$ & $20.0(13 / 65)$ & $14.3(3 / 21)$ & .001 & .003 & .750 \\
\hline $1 \mathrm{y}$ & $5.2(19 / 362)$ & $21.5(14 / 65)$ & $14.3 \%(3 / 21)$ & .033 & .079 & .779 \\
\hline \multicolumn{7}{|l|}{ Survival (\%) } \\
\hline $5 \mathrm{y}$ & 88.3 & 72 & 72.3 & .001 & .086 & .795 \\
\hline $10 \mathrm{y}$ & 72.2 & 64.9 & 62 & .035 & .276 & .886 \\
\hline $5 \mathrm{y}(>30 \mathrm{~d})$ & 92.2 & 84.5 & 79.9 & .059 & .094 & .854 \\
\hline $10 \mathrm{y}(>30 \mathrm{~d})$ & 75.3 & 76.2 & 68.5 & .287 & .293 & .800 \\
\hline
\end{tabular}

risk of death (hazard ratio, $8.1 ; P=.053$ ). Among patients with $\mathrm{R} / \mathrm{As} \mathrm{A}$, concomitant mitral valve replacement and insulin-dependent diabetes mellitus doubled the risk (hazard ratio, 2.2; $P=.061$ and $P=.044$, respectively).

\section{DISCUSSION}

\section{Cohort Analysis}

The overall mean age and gender distribution of our cohort was typical for patients requiring mechanical composite aortic root replacement. ${ }^{13,14} \mathrm{~A}$ history of smoking and chronic hypertension was equally frequent among all etiologies. Cohorts undergoing composite R/AsA repair usually were older than those undergoing valve-sparing procedures, even in reference centers for valve sparing, and included patients with calcified and stenotic disease. ${ }^{7}$ Patients requiring total arch replacement for distal ascending or transverse arch disease represent a distinct group of patients, with often diminished longevity because of the extensive generalized vascular disease determining survival and were, therefore, excluded from the present analysis. ${ }^{7,15}$ Patients requiring aortic root replacement combined with mitral valve surgery represent the other distinct subgroup with a complex operation associated with high morbidity. ${ }^{16}$
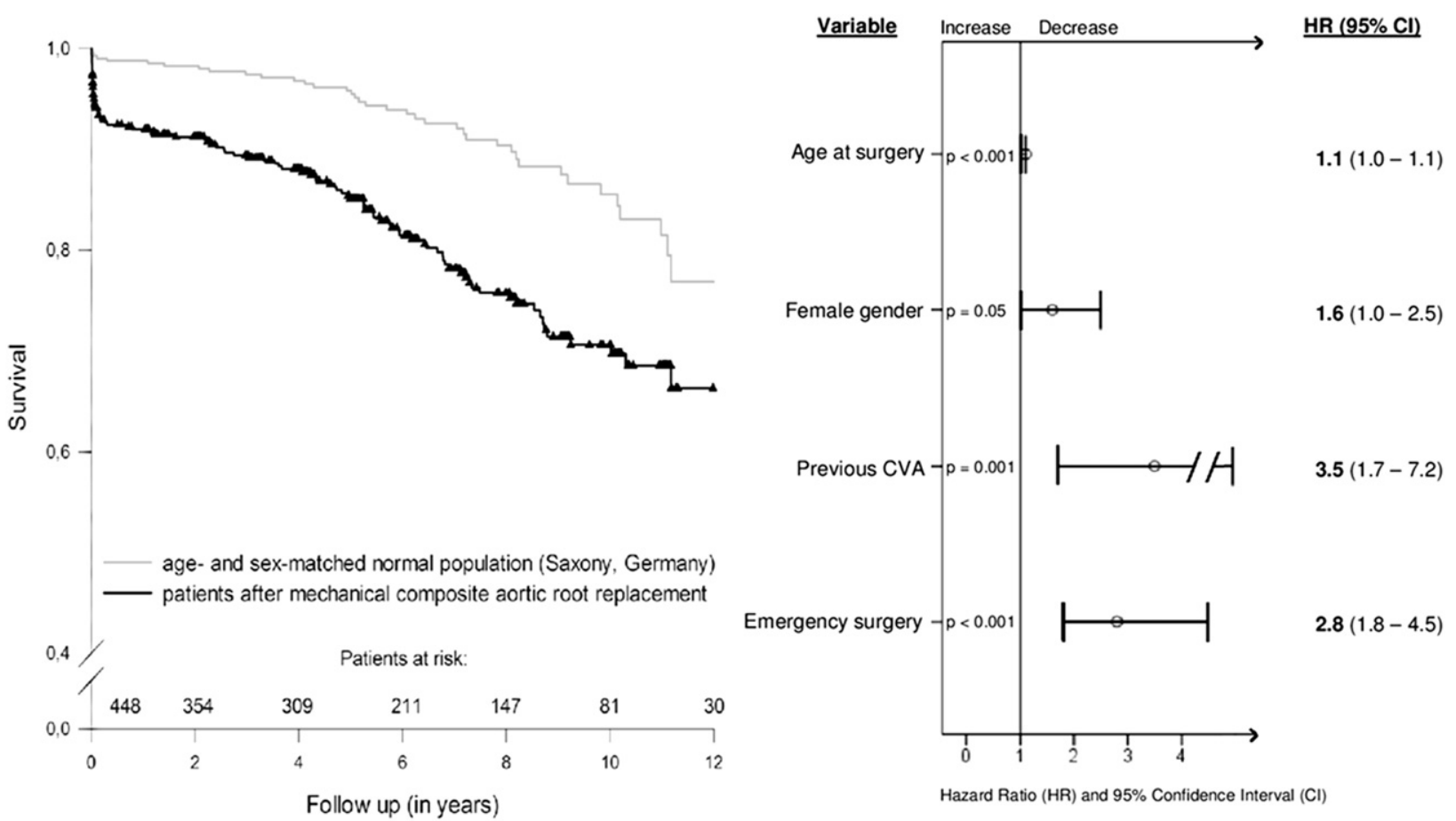

FIGURE 1. Left, Kaplan-Meier long-term survival curve for patients after mechanical composite aortic root replacement and comparison with age- and gender-matched East German population. Right, Multivariate risk factors for long-term survival in Forest plot. Risk factors considered for analysis included age, gender, history of hypertension, insulin-dependent diabetes mellitus, chronic obstructive pulmonary disease, left ventricular ejection fraction, coronary artery disease, number of previous procedures, urgency of procedure, concomitant procedures, concomitant coronary artery bypass grafting, concomitant mitral valve replacement or repair, axillary artery cannulation, and selective cerebral perfusion. CVA, Cerebrovascular accident. 


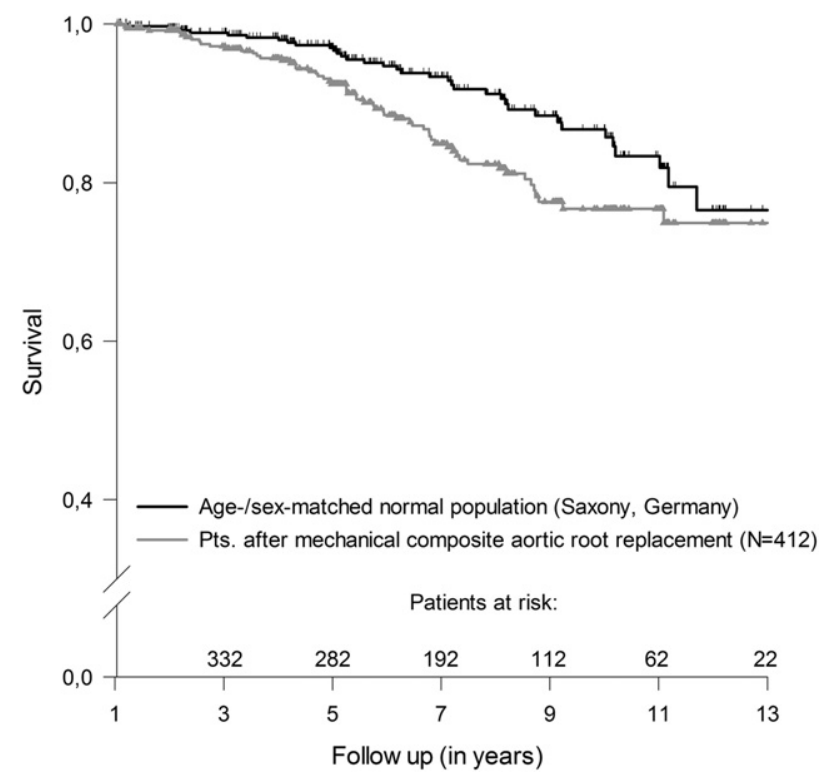

FIGURE 2. Long-term survival after 1 year. Pts., Patients.

\section{Comparison of Intraoperative Data}

The rate of diabetes, chronic obstructive pulmonary disease, and CVAs was unexpectedly low, particularly among patients with aneurysm, even though more than one third were older than 60 years. Direct cannulation was the standard arterial access in $\sim 80 \%$ of elective patients undergoing R/AsA repair, but only $20 \%$ of patients with ADA were cannulated directly. The recent trend toward more

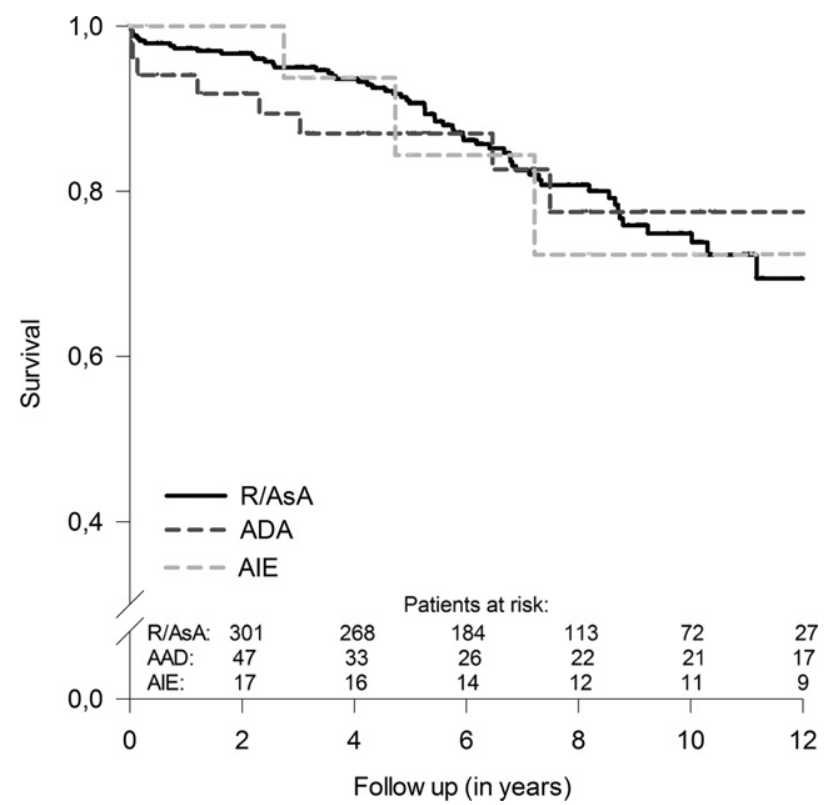

FIGURE 3. Kaplan-Meier survival curve after mechanical composite aortic root replacement for all etiologies (hospital mortality excluded). $A D A$, Acute type A aortic dissection; AIE, active infective endocarditis; $R / A s A$, degenerative or atherosclerotic aortic root/ascending ectasia/aneurysm. frequent axillary cannulation and more restrictive use of the femoral arteries for arterial access reflects the belief that axillary cannulation significantly improves survival and neurologic outcomes after atherosclerotic aneurysm repair of the aortic root and ascending aorta. ${ }^{17}$

\section{Differences and Similarities Between Our Cohort and Others}

In our cohort, fewer than $5 \%$ of patients with aneurysm underwent emergent surgery, reflecting in part the success of our surveillance program in timing the surgery appropriately. The overall hospital mortality was $6.7 \%$, regardless of the etiology, and compares favorably with that from contemporary series of composite root replacement. Hospital mortality for elective composite R/AsA repair was as low as that for elective aortic valve replacement and slightly greater than the reported numbers for contemporary valve-sparing series, likely reflecting the greater percentage of patients with calcified stenosis and more generalized vascular disease and more advanced mean age. Among patients undergoing emergency surgery for ADA, the hospital mortality was comparable to that of other series with likely less severe concomitant pathologic features and lower mean age. The hospital mortality among patients undergoing composite root repair for AIE was rather low; however, the sample size was small, and the patients were relatively young.

The overall 1-year survival, likely representing the true operative mortality for these extensive surgical procedures, was $92 \%$ and significantly different for patients undergoing urgent or emergent surgery for ADA or AIE than for those undergoing primary elective R/AsA $(P=.009$ and $P=.001$, respectively). Thereafter, however, the LMR aligned, and survival beyond 30 days was not significantly different statistically after $5(P=.06-.9)$ or $10(P=.3-.8)$ years (Table 3 ).

\section{Risk Factor Interpretation}

Patient age and crossclamp time clearly-and not surprisingly_were risk factors for overall, early, and longterm mortality, regardless of the etiology. Emergency surgery tripled overall mortality, increased the risk of early death almost sixfold, and influenced longevity, even after hospital discharge or after 30 days, regardless of the etiology. Female gender was a risk factor for overall, early, and long-term mortality, with a hazard ratio of 1.6 and borderline significance $(P=.051$ and $P=.074$; Figure 1). A previous CVA was associated with a threefold increased risk of early mortality and quadrupled the overall mortality, regardless of etiology.

Among the patients with ADA, a reduced left ventricular ejection fraction was associated with an eightfold increase in mortality, likely reflecting the presence of acute ischemia due to coronary compromise. Women with ADA still had a fourfold increased risk of death after discharge and 
beyond 30 days. In patients with AIE, the overall mortality was increased 10-fold, most likely reflecting the deleterious effects of septic emboli. A left ventricular ejection fraction less than $30 \%$ was associated with a six- to eightfold increase in early mortality among those with ADA and $\mathrm{R} /$ AsA but did not reach statistical significance $(P=.073)$.

\section{Freedom From Bleeding and Thromboembolic Events}

The major disadvantage of mechanical composite root replacement is the burden of lifelong anticoagulation. The incidence of severe hemorrhage and thromboembolic events was low-a finding in line with previous reports from similar cohorts.

\section{Implications Regarding Valve Sparing}

We compared an artificially assembled subset of patients potentially eligible for valve-sparing procedures (patients with elective/urgent primary R/AsA and urgent ADA and pure aortic regurgitation). We found their survival in the present series was equivalent to data reported on valvesparing procedures up to 10 years postoperatively (for remodeling and reimplantation, $83 \% \pm 5 \%$ at 8 years and $82.9 \% \pm 3.7 \%$ at 12 years). ${ }^{6,7}$ A less favorable overall outcome, however, would be expected for patients undergoing primary composite Bentall operations than for patients undergoing a David procedure (reimplantation), who have excellent 10 -year survival of $92 \% \pm 3 \%{ }^{18}$ This survival advantage might be related, in part, to the older mean age of patients undergoing composite root replacement (mean age in reimplantation cohort, $45 \pm 15$ years ${ }^{18}$ ) and the inclusion of more severe pathologic findings among the Bentall patients. Freedom from reoperation in the present series was also better among the composite patients than has been reported after valve-sparing procedures ( $98 \%$ vs $95 \%$ at 10 years). Recurrent aortic regurgitation and limited patient eligibility are the major disadvantages of valve-sparing procedures, although the reimplantation technique offers excellent, and potentially superior, results in highly selected patients with mild to moderate regurgitation and normal leaflets.

\section{CONCLUSIONS}

The patients who underwent emergent surgery for ADA and AIE had less favorable short-term outcomes than the patients with R/AsA who underwent elective surgery. Survival after composite root replacement beyond the first year paralleled that of an age- and gender-matched population and was similar for the 3 compared etiologies. Female gender was an independent risk factor for long-term mortality, as described previously for Bentall procedures, although we do not yet have an explanation. Also, previous CVA was a highly significant independent risk factor for death after mechanical aortic root replacement, possibly connected to the enhanced risk entailed in the mandatory use of warfarin and the threat of recurrent fatal CVA.

Composite root replacement remains a choice with excellent durability and freedom from reoperation, particularly for patients with severe and acute etiologies and/or calcified valvular or root disease. Composite root replacement remains a good option, offering excellent longevity, very low reoperation rates, and, likely, fewer bleeding and thromboembolic complications than expected. It deserves serious consideration if conditions for repair are less than perfect.

\section{References}

1. Kouchoukos NT, Karp RB, Lell WA. Replacement of the ascending aorta and aortic valve with a composite graft: results in 25 patients. Ann Thorac Surg. 1977;24:140-8.

2. Bachet J, Termignon JL, Goudot B, Dreyfus G, Piquois A, Brodaty D, et al Aortic root replacement with a composite graft: factors influencing immediate and long-term results. Eur J Cardiothorac Surg. 1996;10:207-13.

3. Galla JD, Lansman SL, Spielvogel D, Minanov OP, Ergin MA, Bodian CA, et al. Bioprosthetic valved conduit aortic root reconstruction: the Mount Sinai experience. Ann Thorac Surg. 2002;74:S1769-72; discussion S92-9.

4. Etz CD, Homann TM, Silovitz D, Spielvogel D, Bodian CA, Luehr M, et al Long-term survival after the Bentall procedure in 206 patients with bicuspid aortic valve. Ann Thorac Surg. 2007;84:1186-93; discussion 93-4.

5. Urbanski PP, Heinz N, Zhan X, Hijazi H, Zacher M, Diegeler A. Modified bioBentall procedure: 10-year experience. Eur J Cardiothorac Surg. 2010;37: 1317-21.

6. David TE, Maganti M, Armstrong S. Aortic root aneurysm: principles of repair and long-term follow-up. J Thorac Cardiovasc Surg. 2010;140(6 suppl):S14-9; discussion S45-51.

7. David TE, Ivanov J, Armstrong S, Feindel CM, Webb GD. Aortic valve-sparing operations in patients with aneurysms of the aortic root or ascending aorta. Ann Thorac Surg. 2002;74:S1758-61; discussion S92-9.

8. David TE. Aortic root aneurysms: remodeling or composite replacement? Ann Thorac Surg. 1997;64:1564-8.

9. Kallenbach K, Pethig K, Schwarz M, Milz A, Haverich A, Harringer W. Valve sparing aortic root reconstruction versus composite replacement-perioperative course and early complications. Eur J Cardiothorac Surg. 2001;20:77-81.

10. Kallenbach K, Karck M, Pak D, Salcher R, Khaladj N, Leyh R, et al. Decade of aortic valve sparing reimplantation: are we pushing the limits too far? Circulation. 2005;112(9 suppl):I253-9.

11. Dagenais F, Bauset R, Mathieu P. Aortic valve-sparing procedure with cusp elongation and free edge reinforcement for bicuspid aortic valve. Ann Thorac Surg. 2005;79:1393-5.

12. Kouchoukos NT. Composite aortic valve replacement and graft replacement of the ascending aorta plus coronary ostial reimplantation: how I do it. Semin Thorac Cardiovasc Surg. 1993;5:66-70.

13. Gelsomino S, Morocutti G, Frassani R, Masullo G, Da Col P, Spedicato L, et al Long-term results of Bentall composite aortic root replacement for ascending aortic aneurysms and dissections. Chest. 2003;124:984-8.

14. Hilgenberg AD, Akins CW, Logan DL, Vlahakes GJ, Buckley MJ, Madsen JC et al. Composite aortic root replacement with direct coronary artery implantation. Ann Thorac Surg. 1996;62:1090-5.

15. Halstead JC, Spielvogel D, Meier DM, Rinke S, Bodian C, Malekan R, et al Composite aortic root replacement in acute type A dissection: time to rethink the indications? Eur J Cardiothorac Surg. 2005;27:626-32; discussion 32-3.

16. David TE, Armstrong S, Maganti M, Ihlberg L. Clinical outcomes of combined aortic root replacement with mitral valve surgery. J Thorac Cardiovasc Surg. 2008; $136: 82-7$.

17. Etz CD, Plestis KA, Kari FA, Silovitz D, Bodian CA, Spielvogel D, et al. Axillary cannulation significantly improves survival and neurologic outcome after atherosclerotic aneurysm repair of the aortic root and ascending aorta. Ann Thorac Surg. 2008;86:441-6; discussion 6-7.

18. David TE, Feindel CM, Webb GD, Colman JM, Armstrong S, Maganti M. Aortic valve preservation in patients with aortic root aneurysm: results of the reimplantation technique. Ann Thorac Surg. 2007;83:S732-5; discussion S85-90. 